\title{
Fluorescence resonance energy transfer in conjugated liposomes
}

\author{
Xuelian Li, Matthew McCarroll and Punit Kohli \\ Department of Chemistry and Biochemistry, \\ Southern Illinois University, \\ Carbondale, IL 62901 \\ pkohli@chem.siu.edu
}

\section{SCHEME 1S.}


Synthesis of 1 : The synthesis of $\boldsymbol{l}$ was accomplished using a modified procedure similar to a published report (Scheme 1S). ${ }^{1}$ All the reagents used were purchased from Fisher Scientific, and were used as received unless otherwise noted. To a solution of 10,12pentacosadiynoic acid (monomer 2, $0.50 \mathrm{~g}, 1.35 \mathrm{mmol}$ from GFS Chemicals) in dry $\mathrm{CH}_{2} \mathrm{Cl}_{2}(10 \mathrm{ml})$ was added $\mathrm{N}$-hydroxysuccinimide $(0.174 \mathrm{~g} 1.5 \mathrm{mmol})$ followed by 1-(3dimethylaminopropyl)-3-ethylcarbodiimide hydrochloride $(0.299 \mathrm{~g}, 1.55 \mathrm{mmol})$. The solution was stirred at room temperature for two hours followed by evaporation of the $\mathrm{CH}_{2} \mathrm{Cl}_{2}$ under reduced pressure. The residue was extracted with diethyl ether and water 
for three times. The organic layer was dried with $\mathrm{MgSO}_{4}$ for half an hour, filtered, and the solvent was removed by rotary evaporation to give $0.45 \mathrm{~g}$ of white solid $\boldsymbol{A}$.

Triethylamine $(0.19 \mathrm{~g})$ and dansyl chloride $(0.40 \mathrm{~g}, 1.49 \mathrm{mmol})$ were added to a solution of $\alpha, \omega$-diamino-triethylene glycol $(1.2 \mathrm{~g}, 11.12 \mathrm{mmol})$ in $50 \mathrm{~mL}$ of THF. After stirring overnight, the solvent was removed by rotary evaporation and the residue was subjected to silica gel column chromatography (ethyl acetate: methanol, 3:1) to give 0.39 $\mathrm{g}$ of the highly fluorescent intermediate $\boldsymbol{B}$.

To a solution of $\boldsymbol{A}(0.6 \mathrm{mmol})$ in $20 \mathrm{~mL} \mathrm{CH}_{2} \mathrm{Cl}_{2}$ was added a solution of fluorescent intermediate $\boldsymbol{B}(0.6 \mathrm{mmol})$ in $\mathrm{CH}_{2} \mathrm{Cl}_{2}$. After stirring overnight at room temperature, the mixture was concentrated by rotary evaporation and the residue was subjected to silica gel column chromatography (from ethyl acetate:hexane :: $2: 1$ to $10 \%$ chloroformmethanol) to yield $0.25 \mathrm{~g}(52 \%)$ of the desired fluorescent monomer $1 .{ }^{1} \mathrm{H}$ NMR (300 $\left.\mathrm{MHz}, \mathrm{CDCl}_{3}\right), \delta .0 .84(\mathrm{t}, 3 \mathrm{H}), 1.10-1.32(\mathrm{~m}, 26 \mathrm{H}), 1.34-1.60(\mathrm{~m}, 6 \mathrm{H}), 2.08-2.20(\mathrm{~m}$, $6 \mathrm{H}), 2.89(\mathrm{~s}, 6 \mathrm{H}), 3.28-3.60(\mathrm{~m}, 12 \mathrm{H}), 5.75(\mathrm{~b}, 1 \mathrm{H}), 6.35(\mathrm{~b}, 1 \mathrm{H}), 7.19-8.61(6 \mathrm{H})$.

Liposome Preparation: The liposomes were synthesized according to a published literature procedure (Figure 1S). ${ }^{1-3}$ A mixture containing 1 and 2 in a ratio of 1:1000 was dissolved in chloroform in a round bottom flask. The solvent was completely evaporated and deionized water was added to give a desired concentration of lipid solution. The suspension was sonicated at a temperature of $\sim 76{ }^{\circ} \mathrm{C}$ for 10 minutes (Sonics \& Materials, Model VCX-500). The solution then was passed through a $0.8 \mu \mathrm{m}$ nylon filter to remove the lipid aggregates, and is cooled at $4{ }^{\circ} \mathrm{C}$ for overnight for self-assembly of monomers. Polymerized diacetylene liposomes were prepared by UV irradiation with $254 \mathrm{~nm}$ for 10 minutes using a Pen Ray UV source $\left(4.5 \mathrm{~mW} / \mathrm{cm}^{2}\right.$ at $\left.1.9 \mathrm{~cm}\right)$. 


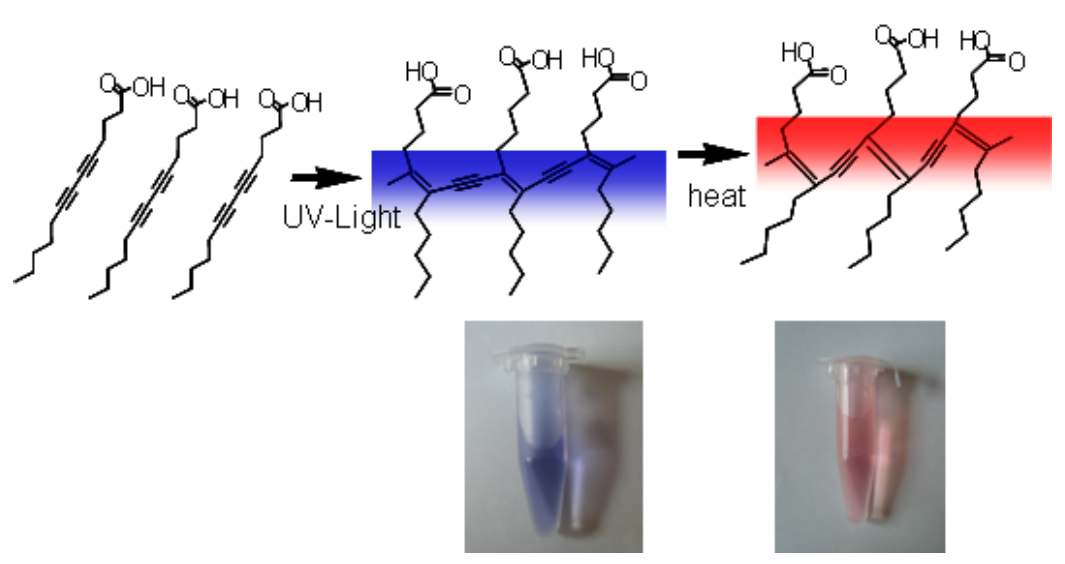

Figure 1S. Schematic self-assembly of monomers and colorimetric changes of PDA liposome solution synthesized. (A) The self-assembly of diacetylenic acid; (B) Photo-polymerization of diacetylene monomers. This gives a blue color solution due to conjugated (ene-yne) polymer backbone. (C) Following thermal treatment on the conjugated polymer changes the blue- to red-form PDA because of decrease in the conjugation length. Optical photographs are shown for blue- and red-form liposomes.

Dialysis Experiments. To investigate the fraction of dansyl-tagged diacetylene monomer 1 that is covalently bound to liposomes, we performed dialysis of polymerized liposomes derived from monomers mixture of $\mathbf{1}$ and $\mathbf{2}$ against deionized water for 24 hours (MWCO of dialysis membrane was $10 \mathrm{kDa}$ ). The emission analysis of dansyl shows that $>95 \%$ of all dansyl fluorophores are incorporated into liposomes. 
Transmission Electron Microscopy: TEM images of liposomes were obtained using a Hitachi S-7100 transmission electron microscope operating at $100 \mathrm{kV}$. The liposome samples were first negatively stained with ( $2 \%$ uranyl acetate or $2 \%$ phosphotungstic acid) and were deposited onto Formvar-coated copper grids (Ted Pella) for TEM images.



Figure 2S. TEM image of PDA liposomes. The average particle size is between 50-150 nm.

Direct Excitation of PDA Liposomes. Figure 3S shows emission spectra of 1 mM PDA liposome solution excited at $470 \mathrm{~nm}$ (direct excitation of PDA chains). There are two emission peaks observed for direct PDA excitation: one prominent peak is centered at $\sim 560 \mathrm{~nm}$ and a shoulder at $\sim 610 \mathrm{~nm}$. The emission spectra of direct excited PDA liposomes is in accordance with recently reported PDA spectra. ${ }^{2}$ Careful examination of Figure $2 \mathrm{~B}$ in the main text reveals that the peak at $610 \mathrm{~nm}$ is present in Figure $2 \mathrm{~B}$ of the main text but it is buried under a more intense peak at $560 \mathrm{~nm}$. The exact nature of peaks at $560 \mathrm{~nm}$ and $610 \mathrm{~nm}$ is not known at this time, but these emission peaks could be due to emission from different chain lengths of PDA excitons. Another possibility is that 610 $\mathrm{nm}$ emission peak is due to radiative transition of the interchain PDA energy transfer to a longer emission wavelength. 


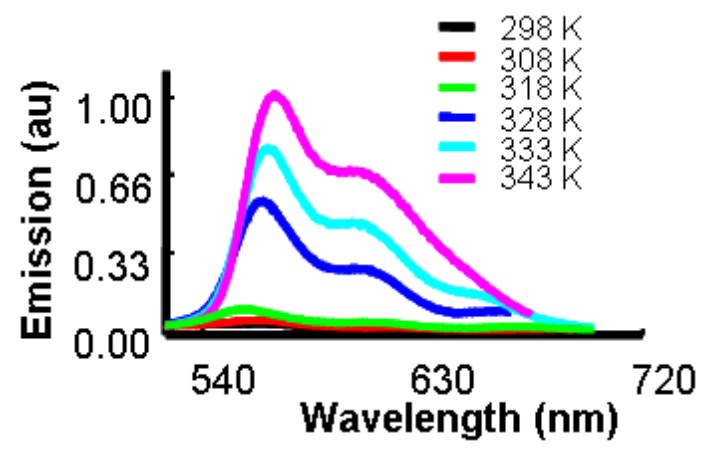

Figure 3S. The emission spectra of a liposome solution derived from monomers of [1] and [2] (mol. ratio $[2] /[1]=1000,\left[\right.$ monomer $\left.\left._{\text {total }}\right]=1 \mathrm{mM}\right)$. The solution was first equilibrated to a desired temperature for 10 minutes and was then cooled to $298 \mathrm{~K}$ followed by equilibrated for 10 minutes at $298 \mathrm{~K}$ before a spectrum was taken. The excitation wavelength is $470 \mathrm{~nm}$ for all the spectra.

\section{References.}

1. (a) Spevak, W.; Nagy, T.O.; Charych, D.H.; Schaefer, M.E.; Gilbert, J.H.; Bednarski, M.D. J. Am. Chem. Soc. 1993, 115, 1146-1147. (b) Ji, E.-K.; Ahn, D. J.; Kim, J. -M. Bull. Korean Chem. Soc. 2003, 24, 667-670.

2. Ma, G.; Muller, A. M.; Bardeen, C. J.; Cheng, Q. Advanced Materials 2006, $18,55-60$.

3. Okada, S.; Peng, S.; Spevak, W.; Charych, D. Acc. Chem. Res. 1998, 31, 229239. 